\title{
Bone mineral density and body composition in Saudi adult females
}

\begin{abstract}
Background: Low bone mass often leads to osteoporosis and increased risk of bone fractures. Body composition is a new aspect may contribute to imbalances that lead to decreased bone mineral density (BMD) and general bone health.

Objective: To determine the relationship between body composition and BMD for adult females in Western Region, KSA. Methods: A cross-sectional study has been conducted on a convenes samples of one hundred adult females. Data were collected through an interview using especial questionnaires. Body composition was measured with the Bodystat ${ } 1500$ and bioelectrical impedance analysis (BIA) was used to determine the visceral fat; Bone mineral density was measured by using the dual-energy x-ray absorptiometry (DEXA).
\end{abstract}

Results: Based on WHO diagnostic criteria, osteoporosis was present in $2 \%$ of samples while osteopenia represented $34 \%$ of the cases. Meanwhile there was a highly positive significant association $(p<0.01)$ between bone mineral density and each of weight, waist, hip, MAC, fat $\%$, fat weight, lean weight, dry lean, body water, BMI, visceral fat. As for spinal BMD, There was a positive significant correlation $(\mathrm{p}<0.01)$ between it and each of weight, MAC, fat weight, lean weight, dry lean, body mass index, Bone mineral density.

Conclusion: A significant portion of adult females is at high risk of development of osteoporosis and increased risk of bone fractures. So young women are in particular need to be aware of their vulnerability to osteoporosis. They can take steps early to slow its progress and prevent complications.
Volume 6 Issue 5 - 2019

\author{
Eslam A Header, ${ }^{1,2}$ Abdullah G Al-Kushi, ${ }^{3}$ Hala \\ MA Wahba, ${ }^{4}$ Hassan M Bukhari, ' Naser A \\ EISawy ${ }^{5}$ \\ 'Clinical Nutrition Department, Faculty of Applied Medical \\ Sciences, Umm al Qura University, Saudi Arabia \\ ${ }^{2}$ Department of Nutrition and Food Science Faculty of Home \\ Economics, Menoufia University, Egypt \\ ${ }^{3}$ Department of Anatomy, Faculty of Medicine, Umm al Qura \\ University, Makkah, Saudi Arabia \\ ${ }^{4}$ Home Economics Department, Faculty of Specific Education, \\ Menoufia University, Egypt \\ ${ }^{5}$ Department of Anatomy and Embryology, Faculty of Medicine \\ Zagazig University, Egypt
}

Correspondence: Naser A EISawy, Department of Anatomy and Embryology, Faculty of Medicine Zagazig University, Egypt, Tel002010284576II,Email nasawy@uqu.edu.sa

Received: September 08, 2019 | Published: September 20, 2019

Keywords: bone, body composition and females

Abbreviations: AMC, arm muscle circumference; BIA, bioelectrical impedance analysis; BMD, bone mass density; BMI, body mass index; KSA, kingdom Saudi Arabia; MAC, mid-arm circumference; MAC, mid-arm circumference; WHO, world health organization

\section{Introduction}

Osteoporosis is a major public health problem worldwide (WHO 2007). It is a skeletal condition characterized by decreased density (mass/volume) of normally mineralized bone. The reduced bone density leads to decreased mechanical strength, thus making the skeleton more likely to fracture. Postmenopausal osteoporosis (Type I) and age-related osteoporosis (Type II) are the most common primary forms of bone loss seen in clinical practice. Secondary causes of osteoporosis include hypercortisolism, hyperthyroidism, hyperparathyroidism, alcohol abuse, and immobilization. ${ }^{1}$

Osteoporosis is a debilitating disease that affects many older people. Fragility fractures are the hallmark of osteoporosis. Although nutrition is only one of many factors that influence bone mass and fragility fractures. ${ }^{2}$

In the development of osteoporosis, there is often a long latent period before the appearance of the main clinical manifestation, pathologic fractures. The earliest symptom of osteoporosis is often an episode of acute back pain caused by a pathologic vertebral compression fracture, or an episode of groin or thigh pain caused by a pathologic hip fracture. ${ }^{1}$
Nutrition is important modifiable factor in the development and maintenance of bone mass and the prevention and treatment of osteoporosis. Approximately $80-90 \%$ of bone mineral content is comprised of calcium and phosphorus. ${ }^{3}$

In the diagnostic process, the extent and severity of bone loss are evaluated and secondary forms of bone loss are excluded. A careful diagnostic work-up that includes clinical history, physical examination, laboratory evaluation. ${ }^{1}$

\section{Objective}

To determine the relationship between body composition and BMD in Saudi adult females in Western Region, KSA.

\section{Subjects and methods}

\section{Study}

Study design is the present cross-sectional descriptive approach.

\section{Target population}

Convenes sample from students and stuff who attended morning shift (8am-3pm) during the study period through the academic year (2016/17) in Faculty of Applied Medical Sciences.

\section{Sample size}

Sample consisted of 100 adult females aged of the samples were 19 - 45 years old. 


\section{Methods}

Data were collected by interview using Questionnaire containing the following: (name, occupation, age, total income and educational level).

Anthropometric measurements: Height was recorded without shoes; using a wall stadiometer to the nearest $1 \mathrm{~mm}$. Subjects were weighed using a clinical balance wearing light clothing and without shoes to the nearest $0.1 \mathrm{~kg}$. BMI was calculated as weight (in $\mathrm{kg}$ ) $/$ height (in $\left.\mathrm{m}^{2}\right){ }^{4}$ The waist circumference was measured at a level midway between the lowest rib and the iliac crest. ${ }^{5}$ The hip circumference may likewise be measured at its widest part of the buttocks or hip. ${ }^{5}$ Arm circumferences measurement: Arm (mid-point in the length of the horizontal line between the acromion process and the tip of the olecranon) circumferences were measured to the nearest $0.1 \mathrm{~cm}$ at each site. ${ }^{6}$ Mid-arm circumference (MAC): Mid-arm circumference (MAC) was measured with a flexible but non-stretchable measuring tape (steel tape) and was recorded to the nearest 0.1 centimeter. It was measured midway between the lateral projection of the acromion process of the scapula and the inferior margin of the olecranon process of the ulna. ${ }^{7}$

Body composition: Bioelectrical impedance analysis (BIA) Bioelectrical impedance analysis is used The Bodystat ${ }^{\circledR} 1500$ to estimate body composition using the difference of conductivity based on the biological characteristic of tissue. Body composition measurement technique based on the principle that lean tissue has higher electrical conduction and lower impedance than fat. It uses resistance and reactance to estimate fat-free and fat mass. ${ }^{8}$
Bone mass density: BMD was measured by using Dual-energy X-ray absorptiometry DEXA (en CORE 2010) device, model 8743, manufactory Lunar, USA. ${ }^{9}$ It is the preferred technique for measuring BM). DXA has also been called dual energy X-ray absorptiometry, or DEXA. Diane reported that a normal BMD is not more than -1SD below the mean value of peak bone mass in young adult women. Osteopenia is indicated by a BMD of between -1 and -2.5 SD below the mean value. The BMD of a patient with osteoporosis is more than $-2.5 \mathrm{SD}$ below the mean value of peak bone mass, and patients with severe osteoporosis exhibit fractures and a BMD of more than -2.5 SD below the mean value. ${ }^{10}$

Statistical analysis: Statistical package spreadsheet software (SPSS) version 16 was used for statistical analysis. Mean $\pm \mathrm{SD}$ and analysis of variance (ANOVA) test were used as appropriate. Qualitative data were expressed as percentages. For comparing the groups, the chisquare test or Fisher's exact test were used for qualitative variables. The results were reported as mean $(95 \%)$. $\mathrm{P}<0.05$ was considered significant.

\section{Results}

\section{Prevalence of osteoporosis}

The frequency distribution of studied sample according to BMD is shown in Table $1 \&$ Figure 1. The sample consisted of 100 adult females, based on WHO diagnostic criteria; osteoporosis was present in $2 \%$ of cases while, osteopenia was current in $34 \%$ of sample.

Table I Frequency distribution of studied samples according to bone mass density

\begin{tabular}{|c|c|c|c|c|c|c|c|}
\hline \multirow[t]{2}{*}{$\begin{array}{l}\text { Groups } \\
\text { Parameters }\end{array}$} & \multicolumn{2}{|c|}{$\begin{array}{l}\text { Normal (T-score* of- I or } \\
\text { more positive) }\end{array}$} & \multicolumn{2}{|c|}{$\begin{array}{l}\text { Osteopenia (T-score } \\
\text { between - I and -2.4) }\end{array}$} & \multicolumn{2}{|c|}{$\begin{array}{l}\text { Osteoporosis ( } \mathrm{T} \text { score of- } 2.5 \\
\text { or more negative) }\end{array}$} & \multirow[t]{2}{*}{ Total } \\
\hline & No. & $\%$ & No. & $\%$ & No. & $\%$ & \\
\hline Sample & 64 & 64 & 34 & 34 & 2 & 2 & 100 \\
\hline
\end{tabular}

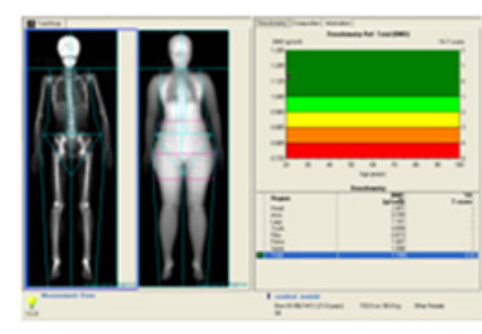

Normal

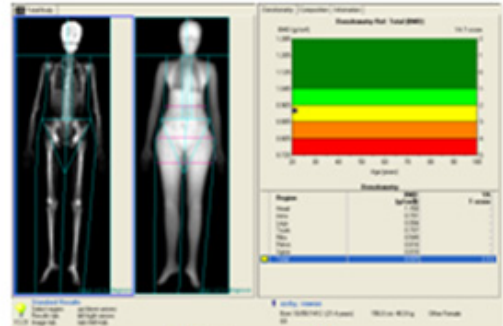

Osteopenia

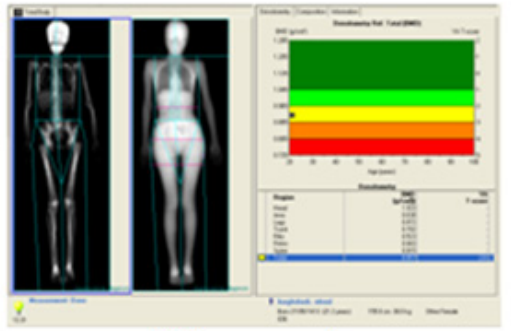

Osteoporosis

Figure I Samples from evaluated cases using DEXA scan. 


\section{Anthropometric measurements}

Table 2 show mean and SD values of anthropometric measurements and age for studied samples. The values of AMC for osteoporotic cases were significantly lower $(\mathrm{P}=0.000)$ than those of osteopenia and normal cases represents $(22.25 \pm 6.72,24.43 \pm 2.572$ and $27.93 \pm 14.44 \mathrm{~cm}$ respectively). In addition, the hip circumference was significantly decreased for osteoporotic cases $(\mathrm{P}=0.032)$ when compared with osteopenia and normal cases, the values were $(99.02 \pm 13.709,92.19 \pm 9.723$ and $90.50 \pm 9.19 \mathrm{~cm}$ respectively), the same trend was noticed in weight $(\mathrm{P}=0.002)$ for osteoporotic cases as compared to osteopenia and normal cases $(59.51 \pm 15.7,49.64 \pm 7.2$ and $46.75 \pm 12.09 \mathrm{~kg}$ respectively). As for age, the mean $\pm \mathrm{SD}$ age was $21.69 \pm 3.66$ years for total samples.

Table 2 Mean $\pm S D$ values of anthropometric measurements and age for studied samples

\begin{tabular}{llllll}
\hline BMD & Normal & Osteopenia & Osteoporosis & Total & ANOVA \\
\cline { 2 - 6 } Parameters & Mean \pm SD & Mean \pm SD & Mean \pm SD & Mean \pm SD & Significance \\
\hline Age $(\mathrm{y})$ & $21.90 \pm 4.29$ & $21.32 \pm 2.22$ & $21.00 \pm .00$ & $21.69 \pm 3.66$ & 0.732 \\
Weight $(\mathrm{kg})$ & $59.51 \pm 15.7$ & $49.64 \pm 7.2$ & $46.75 \pm 12.09$ & $55.90 \pm 14.11$ & 0.002 \\
Height $(\mathrm{cm})$ & $158.20 \pm 5.7$ & $155.87 \pm 10.9$ & $155.25 \pm .35$ & $157.35 \pm 7.81$ & 0.347 \\
Waist $(\mathrm{cm})$ & $76.86 \pm 17.74$ & $73.15 \pm 7.52$ & $68.50 \pm 4.95$ & $75.43 \pm 14.94$ & 0.409 \\
Hip $(\mathrm{cm})$ & $99.02 \pm 13.71$ & $92.19 \pm 9.72$ & $90.50 \pm 9.19$ & $96.53 \pm 12.77$ & 0.032 \\
AMC $(\mathrm{cm})$ & $27.93 \pm 14.44$ & $24.43 \pm 2.57$ & $22.25 \pm 6.72$ & $26.62 \pm 4.28$ & 0 \\
\hline
\end{tabular}

SD, standard deviation; MAC, mid-arm circumference; kg, kilo gram; cm, Centimeter; y, years

Mean values of fat body weight, lean weight and body water for studied sample are shown in Table 3. It is worthy to note that, the fat weight $/ \mathrm{kg}$ for osteoporotic cases was significantly lower $(\mathrm{P}=0.000)$ than that of each of osteoporosis and normal cases represents $(13.84 \pm 3.01$, $18.95 \pm 10.69$ and $18.50 \pm 1.13 \mathrm{~kg}$ respectively.), Also dry lean weight $/ \mathrm{kg}$ for osteopenia cases were significantly lower $(\mathrm{P}=0.000)$ than normal and osteoporotic cases $(35.99 \pm 5.72,41.18 \pm 8.61$ and $36.65 \pm 1.06 \mathrm{~kg}$ resp.). Also, our results revealed that, the mean values of visceral fat/ $\mathrm{kg}$ were decreased for osteoporotic cases as compared with osteopenia and normal cases $(2.50 \pm 2.12,3.29 \pm 1.29,4.09 \pm 1.64 \mathrm{~kg}$ respectively.), The same trend was observed for total body water/L the values were $(25.75 \pm 1.06 \%, 26.82 \pm 5.16$ and $29.02 \pm 3.84 \mathrm{~L}$ respectively.). However, body water \% was decreased for osteoporotic cases as compared with normal and osteopenia cases $(46.70 \pm 1.98,50.65 \pm 6.97,52.96 \pm 4.095 \%$ respectively)

Table 3 Mean $\pm S D$ values of body composition for studied samples

\begin{tabular}{llllll}
\hline BMD & Normal & Osteopenia & Osteoporosis & Total & Anova \\
\cline { 2 - 6 } Parameters & Mean \pm SD & Mean \pm SD & Mean \pm SD & Mean \pm SD & Significance \\
\hline Fat \% & $30.23 \pm 9.03$ & $27.77 \pm 3.66$ & $33.55 \pm 2.05$ & $29.46 \pm 7.62$ & 0.000 \\
Fat weight $(\mathrm{kg})$ & $18.95 \pm 10.7$ & $13.84 \pm 3.01$ & $18.50 \pm 1.13$ & $17.20 \pm 9.04$ & 0.000 \\
Lean weight $(\mathrm{kg})$ & $41.18 \pm 8.61$ & $35.99 \pm 5.72$ & $36.65 \pm 1.06$ & $39.33 \pm 8.01$ & 0.000 \\
Dry lean $(\mathrm{kg})$ & $12.08 \pm 4.61$ & $9.81 \pm 2.59$ & $10.90 \pm .00$ & $11.299 \pm 4.12$ & 0.000 \\
Water \% & $50.65 \pm 6.97$ & $52.96 \pm 4.1$ & $46.70 \pm 1.98$ & $51.36 \pm 6.18$ & 0.052 \\
Body water $(\mathrm{Ltr})$. & $29.02 \pm 3.84$ & $26.82 \pm 5.16$ & $25.75 \pm 1.06$ & $28.21 \pm 4.42$ & 0.197 \\
Visceral fat $(\mathrm{kg})$ & $4.09 \pm 1.64$ & $3.29 \pm 1.29$ & $2.50 \pm 2.12$ & $3.79 \pm 1.58$ & 0.080 \\
\hline
\end{tabular}

SD, standard deviation; kg, kilo gram; Ltr, Liter

Table 4 displays that about $29.5 \%$ of osteopenia cases were underweight. On the other hand, the BMI value of osteopenia cases were significantly lower $(\mathrm{P}=0.002)$ than osteoporosis and normal groups by the mean of $20.04 \pm 2.45,22.95 \pm .07$ and $23.69 \pm 5.649 \mathrm{Kg} /$ respectively. 
Table 4 Body mass index for studied samples

\begin{tabular}{|c|c|c|c|c|c|c|c|c|c|}
\hline \multirow{2}{*}{$\begin{array}{l}\text { BMD } \\
\text { BMI }\end{array}$} & \multicolumn{2}{|c|}{ Normal } & \multicolumn{2}{|c|}{ Osteopenia } & \multicolumn{2}{|c|}{ Osteoporosis } & \multicolumn{2}{|c|}{ Total } & \multirow{2}{*}{$\begin{array}{l}\mathbf{X}^{2} \\
\mathbf{P}\end{array}$} \\
\hline & No. & $\%$ & No. & $\%$ & No. & $\%$ & No. & $\%$ & \\
\hline Underweight $[<18.5]$ & 6 & 9.4 & 9 & 26.5 & - & - & 15 & 15 & $16.211^{a}$ \\
\hline Normal [18.5-24.9] & 39 & 60.9 & 25 & 73.5 & 2.00 & 100 & 66 & 66 & 0.039 \\
\hline Overweight [25-29.9] & 11 & 17.2 & - & - & - & - & II & 11 & \\
\hline Obese I [30-34.9] & 7 & 10.9 & - & - & - & - & 7 & 7 & \\
\hline Obese II [35-39.9] & I & 1.6 & - & - & - & - & I & I & \\
\hline Total & 64 & 100 & 34 & 100 & 2 & 100 & 100 & 100 & \\
\hline BMI & & & & & & & & & ANOVA $P$ \\
\hline Mean $\pm S D$ & \multicolumn{2}{|c|}{$23.69 \pm 5.64$} & \multicolumn{2}{|c|}{$20.04 \pm 2.45$} & \multicolumn{2}{|l|}{$22.95 \pm .07$} & \multicolumn{2}{|c|}{$22.44 \pm 5.02$} & 0.002 \\
\hline
\end{tabular}

$\mathrm{BMI}$, body mass index; $\mathrm{X}^{2}$, Chi-square; $\mathrm{SD}$, standard deviation

\section{Correlation coefficient between BMD and body measurements for studied samples}

Data presented in Table 5 demonstrate the correlation coefficient between BMD and body measurements for studied samples. There was a highly positive significant relationship at level (1\%) between BMD and each of weight, waist, hip, MAC, fat $\%$, fat weight, lean weight, dry lean, body water, BMI, visceral fat, and T score, but it was a negative significant correlation at the same level between it and water $\%$ in the body. As for spinal BMD, here was a positive significant correlation $(\mathrm{p}<0.01)$ between it and each of weight, MAC, fat weight, lean weight, dry lean, BMI, BMD, T score. Meanwhile, there was a positive significant association at level (5\%) between spinal BMD and each of hip, fat $\%$, and body water, nevertheless, it correlated negatively significant $(\mathrm{p}<0.05)$ with visceral fat.

Concerning age, there was a highly positive significant correlations $(p<0.01)$ between age and each of waist, MAC, fat $\%$, fat weight, BMI and visceral fat. Otherwise there was a negative significant correlation at level (5\%) between age and each of hip and T score. Bodyweight correlated significantly positive $(\mathrm{p}<0.01)$ with height, waist, hip, MAC, fat $\%$, fat weight, lean weight, dry lean, body water, BMI, visceral fat, BMD and T score.

Table 5 Correlation coefficient between BMD and body measurements and body measurements for students

\begin{tabular}{|c|c|c|c|c|c|c|c|c|c|c|c|c|c|c|c|c|}
\hline & Age & Weight & Height & Waist & Hip & MAC & Fat\% & $\begin{array}{l}\text { Fat } \\
\text { Weight }\end{array}$ & $\begin{array}{l}\text { Lean } \\
\text { Weight }\end{array}$ & $\begin{array}{l}\text { Dry } \\
\text { Lean }\end{array}$ & $\begin{array}{l}\text { water } \\
\%\end{array}$ & $\begin{array}{l}\text { Body } \\
\text { water }\end{array}$ & BMI & $\begin{array}{l}\text { Viscer. } \\
\text { Fat }\end{array}$ & BMD & $\begin{array}{l}\mathbf{T} \\
\text { score }\end{array}$ \\
\hline Weight & $.281 * *$ & & & & & & & & & & & & & & & \\
\hline Height & $-.013^{* *}$ & $.316 * *$ & & & & & & & & & & & & & & \\
\hline Waist & $.263^{* *}$ & $.450 * *$ & 0.072 & & & & & & & & & & & & & \\
\hline Hip & $.227^{*}$ & $.829 * *$ & $.267^{* *}$ & $0418^{* *}$ & & & & & & & & & & & & \\
\hline MAC & $.304 * *$ & $.866 * *$ & $.209 *$ & $.359 * *$ & $.729 * *$ & & & & & & & & & & & \\
\hline Fat $\%$ & $.340 * *$ & $.711 * *$ & 0.002 & $.437^{* *}$ & $.552^{* * *}$ & $.588 * *$ & & & & & & & & & & \\
\hline $\begin{array}{l}\text { Fat } \\
\text { Weight }\end{array}$ & $.363^{* *}$ & $.903 * *$ & 0.143 & $.493^{* * *}$ & $.740 * *$ & $.760 * *$ & $.92 I^{* *}$ & & & & & & & & & \\
\hline $\begin{array}{l}\text { Lean } \\
\text { Weight }\end{array}$ & .091 & $.885 * *$ & $.400 * *$ & $.350 * *$ & $.704 * *$ & $.754 * *$ & $.463^{* *}$ & $.705^{* *}$ & & & & & & & & \\
\hline $\begin{array}{l}\text { Dry } \\
\text { Lean }\end{array}$ & .022 & $.855^{* * *}$ & $.421^{* *}$ & $.369 * *$ & $.746 * *$ & $.670 * *$ & $.559 * *$ & $.735 * *$ & $.910 * *$ & & & & & & & \\
\hline $\begin{array}{l}\text { water } \\
\%\end{array}$ & $-.339 * *$ & $-.644 * *$ & $-0.166-$ & $-.263^{* *}$ & $-.470^{* *}$ & $-.57 \mid * *$ & $-.759 * *$ & $-.714 * *$ & $-.385 * *$ & $-.440 * *$ & & & & & & \\
\hline $\begin{array}{l}\text { Body } \\
\text { water }\end{array}$ & .126 & $.654 * *$ & 0.208 & $.319 * *$ & $.582 * *$ & $.580 * *$ & $.254 * *$ & $.478^{* *}$ & $.67 I^{* *}$ & $.576 * *$ & $-.252^{* *}$ & & & & & \\
\hline BMI & $.339 * *$ & $.940 * *$ & 0.102 & $.465^{* *}$ & $.778^{* * *}$ & $.850 * *$ & $.808^{* *}$ & $.943 * *$ & $.776 * *$ & $.743 * *$ & $-.678^{* *}$ & $.626 * *$ & & & & \\
\hline $\begin{array}{l}\text { Visceral } \\
\text { Fat }\end{array}$ & $.383 * *$ & $.746 * *$ & .000 & $.338 * *$ & $.580 * *$ & $.737 * *$ & $.625^{* *}$ & $.707 * *$ & $.555 * *$ & $.514 * *$ & $-.615^{* *}$ & $.508 * *$ & $.812^{* * *}$ & & & \\
\hline BMD & 0.122 & $.605 * *$ & 0.165 & $.357^{* *}$ & $.459 * *$ & $.637 * *$ & $.407 * *$ & $.552 * *$ & $.500 * *$ & $.451 * *$ & $-.319 * *$ & $.339 * *$ & $.586 * *$ & $.438 * *$ & & \\
\hline T score & $.218^{*}$ & $.57 I^{* * *}$ & 0.126 & $.334^{* *}$ & $.445^{* *}$ & $.615 * *$ & $.404 * *$ & $.529 * *$ & $.462 * *$ & $.435 * *$ & $-.320^{* *}$ & $.350 * *$ & $.57 I^{* *}$ & $.416 * *$ & $.914 * *$ & \\
\hline $\begin{array}{l}\text { Spinal } \\
\text { BMD }\end{array}$ & 0.064 & $.362 * *$ & 0.136 & $.148^{* * *}$ & $.213^{* *}$ & $.391 * *$ & $.208^{* *}$ & $.293 * *$ & $.327 * *$ & $.298 * *$ & $-.282^{* *}$ & $.244 * *$ & $.319 * *$ & $.245 * *$ & $.453^{* * *}$ & $.433^{* *}$ \\
\hline
\end{tabular}

*Correlation is significant at the 0.05 level

***Correlation is significant at the 0.0 I level 
Nevertheless, waist circumference correlated negatively significant $(\mathrm{p}<0.01)$ with hip, MAC, fat $\%$, fat weight, lean weight, dry lean, body water, BMI, visceral fat, BMD and T score. There was a positive significant relationship $(\mathrm{p}<0.01)$ between fat $\%$ and each of age, weight, waist, hip, MAC, fat $\%$, fat weight, lean weight, dry lean, BMI, visceral fat, BMD, T score. At the same time, there was a positive significant association $(\mathrm{p}<0.01)$ between visceral fat and each of age, weight, waist, hip, MAC, fat $\%$, fat weight, lean weight, dry lean, body water, BMI, BMD, T score. In addition there was a positive significant correlation $(\mathrm{p}<0.05)$ between height and total body water.

\section{Discussion}

Our results revealed that, there was a highly positive significant correlation between BMD and each of weight, waist, hip, MAC, fat $\%$, fat weight, lean weight, dry lean, body water, BMI, visceral fat, and T-score. Meanwhile, spinal BMD correlated significantly $(\mathrm{p}<0.01)$ with each of weight, MAC, fat weight, lean weight, dry lean, BMI, $\mathrm{BMD}$, total T-score.

Body composition is a new aspect affecting bone health and density, it has a huge impact on bones status either by protecting the bone tissues or by decreasing BMD causing increase risk of fractures. This come positively with Gourlay et al. ${ }^{11}$ investigation who reported that, weight was the most important determinants of a BMD at all sites, whoever Lloyd et al. ${ }^{12}$ disagreed with the results which demonstrate a there was association between obesity and osteoporosis in a recent sample of US older adults. Also Michaëlsson et al. ${ }^{13}$ found that weight of over $71 \mathrm{~kg}$ was associated with a very low risk of being osteopenic compared with women weighing less than $64 \mathrm{~kg}$, as well as weight could be used to exclude women from a screening program for postmenopausal osteoporosis.

On the other hand, Nicholas et al. ${ }^{14}$ indicated that, muscle strength, physical fitness, and weight appear to exert independent effects upon bone mass. Age effects may be mediated indirectly through associated changes in these factors. The integrated physical load on the skeleton may be a final common pathway. Meanwhile Wardlaw ${ }^{15}$ reported that, other explanations include increased hormonal circulation in obese women and greater conversion of adrenal androgens to estrogens linked to greater mass of adipose tissue. Currently no value is agreed on for weight-to-height versus osteoporosis and related fracture risk, but some extra fat mass yielding a body mass index $>26-28$ does confer limited protection, whereas a slender figure yielding a body mass index $<22-24$ increases risk. In another study published by Nicholas et al. ${ }^{14}$ found that, muscle strength was an independent predictor of BMD at all three sites in the proximal femur as well as in the lumbar spine and forearm; proximal femur BMD was also predicted by physical fitness. BMI was a positive predictor of bone mass at all sites. In the proximal femur, age was not an independent predictor of BMD at any site.

Meanwhile Wardlaw ${ }^{15}$ reported that, numerous diet and lifestyle factors, including body weight, influence BMD, and in turn, fracture risk. BMD in the total body, hip, lumbar spine, and radius is weakly to moderately correlated to body weight, fat mass, and lean body mass in adolescent, premenopausal, and elderly women, possibly as the result of stress on the skeleton from the mechanical loading of body weight alone. In addition, greater lean body mass may be a cause.

Nicholas et al. ${ }^{14}$ supposed that, in postmenopausal women muscle strength was a significant predictor of bone mass in the femur and forearm, but not in the spine. However, BMI remained predictive of bone mineral at all sites. On the other hand, Kathryn et al. ${ }^{16}$ light exposure can influence sleep and circadian timing, both of which have been shown to influence weight regulation. The full model accounted for $34.7 \%$ of the variance in BMI $(\mathrm{p}=0.01)$. Exposure to moderate levels of light at biologically appropriate times can influence weight, independent of sleep timing and duration. ElSawy et al. ${ }^{17}$ noticed that the majority of male and female students have overweight (BMI equal $\left.18-24.9 \mathrm{Kg} / \mathrm{m}^{2}\right)$ with $(39 \%$ and $55 \%)$ respectively, furthermore all osteoporotic male were overweight, meanwhile about $33.3 \%$ of female were obese.

Our research showed that, AMC for osteoporosis cases was significantly lower $(\mathrm{P}=0.000)$ than osteopenia and normal cases represents as well as for the hip and the same were noticed in weight significant reduction $(\mathrm{P}=0.002)$ for osteoporosis cases than osteopenia and normal as represented. These results have the different opinion with Lehmann et al. ${ }^{18}$ investigation the relatives risk (RRs) for hip and spine fractures were negatively associated with current body mass index, current weight, and weight gain since the age of 25years. Moreover, the RRs of these fractures were positively associated with current height.

Our results revealed that the fat $\%$ for osteopenia patients was significantly lower than osteoporosis and normal cases, the dry lean weight $\mathrm{kg}$ for osteopenia patients was significantly lower than osteoporosis and normal cases, also we observed that visceral fat was the lowest in osteoporosis patients while the it was the highest in the body water and total body water (Ltr), these results were in agreement with Maryfran et al. ${ }^{19}$ who reported that, bone mineral density of the proximal femur was similar and significantly greater in the thigh muscle/low fat and high muscle/high fat body composition subgroups compared with bone mineral density in the seven other groups, while Aloia et al..$^{20}$ disagree as they reported that they found no evidence that adiposity plays a major role in protecting against bone loss.

The average value of BMI for osteopenia patients was significantly higher compared with osteoporosis and normal cases. Meanwhile, these results didn't show any significant differences between studied samples. Although Emaus et al. ${ }^{21}$ found BMI had not the strongest effect on BMD, especially in the oldest age groups, but a BMI above $30 \mathrm{~kg} / \mathrm{m}^{2}$ did not exert any additional effect compared to the population average BMI of $27 \mathrm{~kg} / \mathrm{m}^{2}$. At the age of 80 years, a lifestyle of moderate BMI to light overweight. Moreever Van der Voort et al..$^{22}$ Although age and BMI are the strongest risk factors for osteoporosis, they are of less significance when used for screening the population for osteoporosis. On the other hand Glauber et al. ${ }^{23}$ mentioned that, Weight did not seem to influence the relationship between BMD and age. In sum, at weight bearing-sites, the preponderance of the effect of weight on BMD is a direct result of mass effects rather than adiposity, whereas at non-weight-bearing sites, adiposity exerts more important effects, potentially mediated by metabolic factors. Concerning age, there was a highly positive significant connection between age and impedance. Otherwise there was a negative significant correlation at level between age and each of lean weight, basal metabolic rate and marital status. Meanwhile a highly positive significant association was observed among marital status and family size. Our results agree with those Gilbert \& Julio ${ }^{24}$ who reported that lean body mass, declines progressively during adult life. The rate of decline tends to speed up in later years. Jebb et al. ${ }^{25}$ had an opposite opinion, as they have found no evidence in this group of obese women that weight cycling led to a progressive decrease in BMR or increase in the proportion of body fat. Meanwhile, Han et al. ${ }^{26}$ also reported that height and age had limited influences on the differences in waist between Caucasian subjects of different stature. Nevertheless, waist circumference correlated 
negatively significant with BME, waist and impedance. In addition, Aaron et al. ${ }^{27}$ investigated that Waist/hip circumference ratio is a better marker than body mass index of risk of death in older women. Thord et al. ${ }^{28}$ noticed that, the total body water was significantly lower than that predicted from the observed body weight $(\mathrm{P}>0.001)$, as was the extracellular water $(\mathrm{P}>0.001)$ and the extracellular/intracellular water quotient $(\mathrm{P}>0.001)$. On average, the body cell mass was similar to the predicted value, but the observed/predicted body cell mass ratio correlated positively with age at follow-up.

A correlation was found between body composition and BMD of the forearm in young Japanese females aged 18 through 40 years who had undergone an Annual Women's Health Examination. The results showed a positive correlation between BMD and body mass index (BMI) and an inverse correlation between BMD and body fat percentage $(\mathrm{BF} \%) .{ }^{29}$ There has been a strong and clear relationship between exercise and osteoporosis as we found out in our results that $100 \%$ of the osteoporosis don't play any sports compared with $85.3 \%$ of the osteopenia and $81.3 \%$ of the normal cases. These results supported by Sinaki ${ }^{30}$ findings which reported that inactivity can cause bone loss, whereas weight-bearing exercises may maintain or improve bone mineral density. There is a significant correlation between muscle strength and bone mineral density. Other researches indicated that childhood and adolescence are particularly valuable times to improve bone mass through exercise. ${ }^{31}$ Higher levels of leisure time, sport activity, and household chores and fewer hours of sitting daily were associated with a significantly reduced relative risk for hip fracture. ${ }^{32}$ Physical activity and fitness reduce risk of osteoporosis and fracture ${ }^{33}$ and fall-related injuries. ${ }^{34}$ Epidemiologic evidence suggests that physical activity is associated with reductions in hip fracture in women and men. ${ }^{35}$ Studies have shown that bone mineral density in postmenopausal women can be maintained or increased with therapeutic exercise. ${ }^{36}$

A higher than usually recommended level of physical activity for adult premenopausal women is associated with higher bone mineral content and total non-fat soft tissue mass, lower body fat mass, and higher BMD. ${ }^{37}$ In the frail elderly, activity to improve balance and confidence may be valuable in fall prevention. Studies have shown that individuals who practice tai chi have a $47 \%$ decrease in falls and $25 \%$ the hip fracture rate of those who do not and that tai chi can be beneficial for retarding bone loss in weight-bearing bones in early postmenopausal women. Intensive exercise training can lead to improvements in strength and function in elderly patients who have had hip replacement surgery due to hip fracture. ${ }^{38}$

Elsawy et al. ${ }^{17}$ \& Puttapitakpong et al.${ }^{39}$ showed that, despite having certain knowledge about osteoporosis, the young women did not seem to have appropriate osteoporosis preventive behaviours. Developing a right attitude towards osteoporosis may be a key determinant to improving health practices in order to prevent osteoporosis.

\section{Conclusion}

A significant portion of adult females are at high risk of development of osteoporosis and increased risk of bone fractures. So young women in particular need to be aware of their risk for osteoporosis. They can take steps early to slow its progress and prevent complications.

\section{Acknowledgments}

No acknowledgments

\section{Conflicts of interest}

No conflict of interest exists.

\section{References}

1. Glaser DL, Kaplan FS. Osteoporosis: definition and clinical presentation. Spine (Phila Pa 1976). 1997;22(24 Suppl):12S-16S.

2. Kevin DC. Diet, Nutrition, and bone health. J Nutr. 2007;137(11 Suppl):2507S-2512S

3. Ilich JZ, Kerstetter JE. Nutrition in bone health revisited: a story beyond calcium. J Am Coll Nutr. 2000;19(6):715-737.

4. Garrow JS, Webster J. Quetelet's index (W/H2) as a measure of fatness. Int J Obes. 1985;9(2):147-153.

5. Han T, Van Leer E, Seidell J, et al. Waist circumference action levels in the identification of cardiovascular risk factors: prevalence study in a random sample. BMJ. 311(7017):1401-1405.

6. Hodgkin E, Hamlin MJ, Ross JJ, et al. Obesity, energy intake and physical activity in rural and urban New Zealand children. Rural Remote Health. 2010;10(2):1336.

7. Michele G, Sara L, Sandra D. Nutrition in Patient Care. In: Sandra DeYoung, editor. Foundations and clinical applications of nutrition: a nursing approach. 3rd ed. Elsevier Health Sciences. 2004:406-407.

8. http://www.bodystat.ca/1500/Product1-Details/Bodystat-1500.aspx

9. Boudousq V. Image resolution and magnification using a cone beam densitometer: optimizing data acquisition for hip morphometric analysis. Osteoporos Int. 2005;16(7):813-822.

10. Diane B. Bioidentical hormones in the treatment of osteoporosis. Int $J$ Pharm Compd. 2001;5(5):335-341.

11. Gourlay ML, Hammett-Stabler CA, Renner JB, et al. Associations between body composition, hormonal and lifestyle factors, bone turnover, and BMD. J Bone Metab. 2014;21(1):61-68.

12. Lloyd JT, Alley DE, Hawkes WG, et al. Body mass index is positively associated with bone mineral density in US older adults. Arch Osteoporos. $9(1): 175$.

13. Michaëlsson K, Lithell H, Vessby B, et al. Serum retinol levels and the risk of fracture. $N$ Engl J Med. 2003;348(4):287-294.

14. Nicholas P, John E, Tom G, et al. Muscle strength, physical fitness, and weight but not age predict femoral neck bone mass. J Bone Miner Res. 1989;4(3):441-448.

15. Wardlaw GM. Putting body weight and osteoporosis into perspective. $A m$ J Clin Nutr. 1996;63(3 Suppl):433S-436S.

16. Kathryn JR, Giovanni S, Kelly GB, et al. Timing and intensity of light correlate with body weight in adults. PLoS One. 2014;9(4):e92251.

17. ElSawy NA, Bukhari HM, Ibrahim S Nada, et al. Obesity and Osteoporosis Among Students in Umm Al-Qura University Makkah, KSA. J VRI Bio Med Chem. 2014;2(2):29-35.

18. Gunnes M1, Lehmann EH, Mellstrom D, et al. The relationship between anthropometric measurements and fractures in women. Bone. 1996;19(4):407-413.

19. Sowers MF, Kshirsagar A, Crutchfield MM, et al. Joint influence of fat and lean body composition compartments on femoral bone mineral density in premenopausal women. Am J Epidemiol. 1992;136(3):257-265.

20. Aloia JF, McGowan DM, Vaswani AN, et al. Relationship of menopause to skeletal and muscle mass. Am J Clin Nutr. 1991;53(6):1378-1383. 
21. Emaus N, Wilsgaard T, Ahmed LA. Impacts of body mass index, physical activity, and smoking on femoral bone loss. the tromsø study. $J$ Bone Miner Res. 2014;29(9):2080-2089.

22. Van der Voort DJ, Brandon S, Dinant GJ, et al. Screening for osteoporosis using easily obtainable biometrical data: diagnostic accuracy of measured, self-reported and recalled BMI, and related costs of bone mineral density measurements. Osteoporos Int. 2000;11(3):233-239.

23. Glauber HS, Vollmer WM, Nevitt MC, et al. Body weight versus body fat distribution, adiposity, and frame size as predictors of bone density. J Clin Endocrinol Metab. 1995;80(4):1118-1123.

24. Gilbert BF, Julio CR. Adult lean body mass declines with age: some longitudinal observations. Metabolism. 1970;19(9):653-663.

25. Jebb SA, Goldberg GR, Coward WA, et al. Effects of weight cycling caused by intermittent dieting on metabolic rate and body composition in obese women. Int J Obes. 1991;15(5):367-374.

26. Han TS, Seidell JC, Currall JE, et al. The influence of height and age on waist circumference as an index of adiposity in adults. Int $J$ Obes Relat Metab Disord. 1997;21(1):83-89.

27. Aaron RF, Susan AK, Thomas AS, et al. Body fat distribution and 5-year risk of death in older women. JAMA. 1993;269(4):483-487.

28. Rosén T, Bosaeus I, Tölli J, et al. Increased body fat mass and decreased extracellular fluid volume in adults with growth hormone deficiency. Clin Endocrinol (Oxf). 1993;38(1):63-71.

29. Arimatsu M, Kitano T, Kitano N, et al. Correlation between bone mineral density and body composition in Japanese females aged 18-40 years with low forearm bone mineral density. Environ Health Prev Med. 2009;14(1):46-51

30. Sinaki M. Exercise and osteoporosis. Arch Phys Med Rehabil 1989;70(3):220-229.
31. Linden C, Ahlborg HG, Besjakov J, et al. A school curriculum-based exercise program increases bone mineral accrual and bone size in prepubertal girls: two-year data from the pediatric osteoporosis prevention (POP) study. J of Bone Miner Res. 2006;21(6):829-835.

32. Feskanich D, Willett W, Colditz G. Walking and leisure-time activity and risk of hip fracture in postmenopausal women. JAMA. 2002;288(18):2300-2306.

33. Karlsson M. Has exercise an antifracture efficacy in women? Scand $J$ Med Sci Sports. 2004;14(1):2-15.

34. Robertson MC, Campbell AJ, Gardner MM, et al. Preventing injuries in older people by preventing falls: a meta-analysis of individual-level data. $J$ of Am Geriatr Soc. 2002;50(5):905-911.

35. Karlsson M. Does exercise reduce the burden of fractures? A review. Acta Orthop Scand. 2002;73(6):691-705.

36. Kemmler W, Lauber D, Weineck J, et al. Benefits of 2 years of intense exercise on bone density, physical fitness, and blood lipids in early postmenopausal osteopenic women: results of the Erlangen Fitness Osteoporosis Prevention Study (EFOPS). Arch Intern Med. 2004;164(10):1084-1091.

37. Fernando D, Fabiana S. Bone mineral density and body composition of adult premenopausal women with three levels of physical activity. $J$ Osteoporos. 2013;2013:953271.

38. Hauer K, Specht N, Schuler M, et al. Intensive physical training in geriatric patients after severe falls and hip surgery. Age Ageing. 2002;31(1):49-57.

39. Puttapitakpong $\mathrm{P}$, Chaikittisilpa S, Panyakhamlerd $\mathrm{K}$, et al. Intercorrelation of knowledge, attitude, and osteoporosis preventive behaviors in women around the age of peak bone mass. BMC Womens Health. 2014;14(1):35. 